medRxiv preprint doi: https://doi.org/10.1101/2022.01.22.22269640; this version posted January $23,2022$. The copyright holder for this preprint (which was not certified by peer review) is the author/funder, who has granted medRxiv a license to display the preprint in It is made available under a CC-BY-NC-ND 4.0 International license .

\title{
Expert Surgeons and Deep Learning Models Can Predict the Outcome of Surgical Hemorrhage from One Minute of Video
}

3

4 Dhiraj J Pangal BS ${ }^{1}$, Guillaume Kugener MEng ${ }^{1}$, Yichao Zhu BS ${ }^{2}$, Aditya Sinha BS ${ }^{1}$, Vyom Unadkat

$5 \mathrm{BS}^{2}$, David J Cote $\mathrm{MD}, \mathrm{PhD}^{1}$, Ben Strickland $\mathrm{MD}^{1}$, Martin Rutkowski $\mathrm{MD}^{3}$, Andrew Hung $\mathrm{MD}^{4}$,

6 Animashree Anandkumar $\mathrm{PhD}^{5,6}$, X.Y. Han $\mathrm{MS}^{7}$, Vardan Papyan $\mathrm{PhD}^{8}$, Bozena Wrobel MD 9 , Gabriel

7 Zada MD MS ${ }^{1}$, Daniel A Donoho MD*10

8

${ }^{1}$ Department of Neurosurgery, Keck School of Medicine of the University of Southern California, Los Angeles CA

${ }^{2}$ Viterbi School of Engineering, University of Southern California, Los Angeles, CA

${ }^{3}$ Department of Neurosurgery, Medical College of Georgia, Augusta, GA

${ }^{4}$ Center for Robotic Simulation and Education, USC Institute of Urology, Keck School of Medicine of the University of Southern California, Los Angeles CA

${ }^{5}$ Department of Computer Science + Mathematics, California Institute of Technology, Pasadena CA

${ }^{6}$ Nvidia Corp., Santa Clara CA

${ }^{7}$ Department of Operations Research and Information Engineering, Cornell University, Ithaca NY

${ }^{8}$ Department of Mathematics, University of Toronto, Ontario, Canada

${ }^{9}$ Department of Otolaryngology, Keck School of Medicine of the University of Southern California, Los Angeles CA

${ }^{10}$ Division of Neurosurgery, Center for Neuroscience, Children's National Hospital, Washington DC

Corresponding Author*:

Daniel A. Donoho MD

Division of Neurosurgery

Center for Neuroscience, Children's National Hospital

Washington DC 20010

danieldonohomd@gmail.com

Office Phone: (202)-476-3020

\section{2}

\section{Word Count (Manuscript): 3065}

\section{Competing Interests: The authors declare that there are no competing interests}

Author Contributions:

Study Design: DJP, GK, AS, GZ, DAD

Data Acquisition: DJP, GK, BS, MR, GZ, DAD

Model Development: DJP, GK, AS, VU, XH, VP, DAD

Statistical Analysis: DJP, GK, DAD

Writing- Original Draft: DJP, GK, DAD

Writing- Revisions: All Authors

Final Approval: All Authors

Study Supervision: GZ, DAD 
medRxiv preprint doi: https://doi.org/10.1101/2022.01.22.22269640; this version posted January 23, 2022. The copyright holder for this preprint (which was not certified by peer review) is the author/funder, who has granted medRxiv a license to display the preprint in It is made available under a CC-BY-NC-ND 4.0 International license .

\section{Abstract}

Background: Major vascular injury resulting in uncontrolled bleeding is a catastrophic and often fatal complication of minimally invasive surgery. At the outset of these events, surgeons do not know how much blood will be lost or whether they will successfully control the hemorrhage (achieve hemostasis). We evaluate the ability of a deep learning neural network (DNN) to predict hemostasis control ability using the first minute of surgical video and compare model performance with human experts viewing the same video.

Methods: The publicly available SOCAL dataset contains 147 videos of attending and resident surgeons managing hemorrhage in a validated, high-fidelity cadaveric simulator. Videos are labeled with outcome and blood loss (mL). The first minute of 20 videos was shown to four, blinded, fellowship trained skull-base neurosurgery instructors, and to SOCALNet (a DNN trained on SOCAL videos). SOCALNet architecture included a convolutional network (ResNet) identifying spatial features and a recurrent network identifying temporal features (LSTM). Experts independently assessed surgeon skill, predicted outcome and blood loss $(\mathrm{mL})$. Outcome and blood loss predictions were compared with SOCALNet.

Results: Expert inter-rater reliability was 0.95 . Experts correctly predicted 14/20 trials (Sensitivity: 82\%, Specificity: 55\%, Positive Predictive Value (PPV): 69\%, Negative Predictive Value (NPV): $71 \%$ ). SOCALNet correctly predicted $17 / 20$ trials (Sensitivity 100\%, Specificity $66 \%$, PPV 79\%, NPV 100\%) and correctly identified all successful attempts.

Expert predictions of the highest and lowest skill surgeons and expert predictions reported with maximum confidence were more accurate. Experts systematically underestimated blood loss (mean error - $131 \mathrm{~mL}$, RMSE $350 \mathrm{~mL}, \mathrm{R}^{2} 0.70$ ) and fewer than half of expert predictions identified blood loss $>500 \mathrm{~mL}(47.5 \%, 19 / 40)$. SOCALNet had superior performance (mean error $-57 \mathrm{~mL}$, RMSE $\left.295 \mathrm{~mL}, \mathrm{R}^{2} 0.74\right)$ and detected most episodes of blood loss $>500 \mathrm{~mL}(80 \%, 8 / 10)$.

In validation experiments, SOCALNet evaluation of a critical on-screen surgical maneuver and high/low-skill composite videos were concordant with expert evaluation.

Conclusion: Using only the first minute of video, experts and SOCALNet can predict outcome and blood loss during surgical hemorrhage. Experts systematically underestimated blood loss, and SOCALNet had no false negatives. DNNs can provide accurate, meaningful assessments of surgical video. We call for the creation of datasets of surgical adverse events for quality improvement research. 
medRxiv preprint doi: https://doi.org/10.1101/2022.01.22.22269640; this version posted January 23, 2022. The copyright holder for this preprint (which was not certified by peer review) is the author/funder, who has granted medRxiv a license to display the preprint in It is made available under a CC-BY-NC-ND 4.0 International license .

\section{Expert Surgeons and Deep Learning Models Can Predict the Outcome of Surgical Hemorrhage from One Minute of Video}

\section{Introduction:}

Major bleeding complications during minimal access, endoscopic or robotic-assisted surgery can impair visualization and requires immediate action to control. ${ }^{1,2}$ Despite maximal efforts, including the conversion from minimally invasive to 'open' surgery, 13-60\% of major vascular injuries result in patient death..$^{2-6}$ Surgeon assessments of the likelihood of achieving hemostasis and the need for blood transfusion should be made immediately; however, inexperience, inability ${ }^{7-11}$ and stress ${ }^{1,3,12,13}$ impair decision-making, and surgeon self-assessments of the likelihood of controlling an unexpected vascular complication are uncorrelated with their actual performance. ${ }^{14}$ Inaccurate predictions of blood loss and task outcome risk patient harm by delaying changes in technique, aid from surgical colleagues, or transfusion of blood products. Rather than waiting for a patient's clinical deterioration, early prediction of difficulty at achieving hemostasis and high-volume blood loss using computer vision (CV) techniques could optimize patient outcomes.

We created SOCAL (Simulated Outcomes following Carotid Artery Laceration), a video dataset of attending and resident surgeons (otorhinolaryngologists and neurosurgeons) controlling life-threatening internal carotid artery injury (ICAI) in a validated, high-fidelity bleeding cadaveric simulator. ${ }^{14-18}$ Carotid injury is a catastrophic complication of endonasal surgery and results in up to $30 \%$ mortality, similar to vascular injuries during minimally-invasive abdominal and thoracic surgery. ${ }^{5,19,20}$ In prior work, we applied artificial intelligence (AI) methods to SOCAL video and developed tools that quantify blood loss and measure surgeon performance metrics from video. ${ }^{21,22}$ Using these tools, we showed that video contains signals of surgical task outcome, but we do not know whether the model can detect predictive signals early in a bleeding episode, nor its performance compared to gold-standard human experts

We provided human experts (fellowship trained skull-base neurosurgeons) with the first minute of 20 videos from SOCAL ('Test Set') and collected predictions of blood loss and task success over the entire unseen task. Experts' predictions of outcome and blood loss established a benchmark of human performance. We then built a deep learning neural network (DNN) trained on the SOCAL video dataset (excluding the Test Set), called SOCALNet, and compared model performance on the Test Set to expert benchmarks. We validated SOCALNet predictions in subsequent experiments. To the authors knowledge this is the first comparison of DNN-derived surgical video outcome prediction to human experts viewing the same video. 
medRxiv preprint doi: https://doi.org/10.1101/2022.01.22.22269640; this version posted January 23, 2022. The copyright holder for this preprint (which was not certified by peer review) is the author/funder, who has granted medRxiv a license to display the preprint in It is made available under a CC-BY-NC-ND 4.0 International license .

\section{Methods:}

123 Experimental Design:

124 Experimental setup, data collection, consent and implementation parameters for the dataset are found 125 in Appendix 1. Seventy-five surgeons ranging from junior trainees to world experts on endoscopic 126 endonasal approaches (EEA) were recorded in a nationwide, validated, high-fidelity training exercise.

127 Surgeons attempted to control an ICAI in a cadaveric head perfused with blood substitute. Performance 128 data and intraoperative video was used to develop the SOCAL database. ${ }^{14-18,23}$ The SOCAL database 129 was developed in concordance with previously published methods, and is publicly available. ${ }^{23-25}$ The 130 SQUIRE reporting guidelines were followed. ${ }^{26}$ The study was approved by the IRB of the University 131 of Southern California. All research was performed in accordance with relevant regulations/guidelines.

132 No patient data was utilized therefore patient-level informed consent was waived. Participating 133 surgeons' consent was obtained for intraoperative video recording. Surgeon-expert consent was 134 obtained.

136 Datasets:

137 The 147 videos in SOCAL were divided into a training set of 127 videos and a separate test set of 20 138 videos. Ten videos depicting successes and 10 of failure were initially chosen at random for the test set; ultimately, 11 success videos (and 9 failures) were used due to ease of video formatting. Videos were truncated after 60 seconds. Only videos in the test set were shown to experts for grading.

SOCALNet Model Development:

143 See eSupp1 for model code. Video was sampled at 1 frame-per-second (fps) and input into two layers, 144 a feature generating layer and a temporal analysis algorithm (Figure 1). The output of the model was a binary prediction of surgical ability (trial success or failure) and estimated blood loss over the entire trial (in milliliters).

147 For the feature generator, we utilized a Residual Learning Neural Network (ResNet) model pretrained 148 on the ImageNet 2012 classification dataset. ${ }^{27,28}$ ResNet is a single-stage convolutional neural network

$149(\mathrm{CNN})$ which uses skip connections to allow for large networks with many layers to skip layers that 150 hurt overall performance. ResNet has become ubiquitous for object detection and classification in 151 computer vision $(\mathrm{CV}) .{ }^{28}$ The final three layers of the ResNet were retrained on SOCAL images to detect 152 features indicative of blood loss or task success. Features from the penultimate layer of the ResNet and 153 manual instrument annotations were passed into a bi-layer Long Short-Term Memory (LSTM) recurrent neural network. ${ }^{29}$ LSTM cells contain an input, output and forget gate, allowing the network to regulate the flow of information across cells. Instrument annotations alone are inadequate for outcome prediction; successful detectors incorporate instrument data and image features. ${ }^{21}$ 
medRxiv preprint doi: https://doi.org/10.1101/2022.01.22.22269640; this version posted January 23, 2022. The copyright holder for this preprint (which was not certified by peer review) is the author/funder, who has granted medRxiv a license to display the preprint in It is made available under a CC-BY-NC-ND 4.0 International license .

159 Experts were four skull base fellowship-trained neurosurgeon instructors in ICAI management. Experts

160 watched the 20, one-minute test videos and provided: blood loss estimates (in $\mathrm{mL}$ ), outcome predictions

161 (success/failure), and surgeon grades (1-5 Likert scale, 1 represents novice and 5 represents master).

162 Experts also reported self-confidence in their outcome prediction (1-5 Likert scale; 5 represents most

163 confident). Prior to grading, experts watched anchoring videos of novice, average, and master

164 performances with respective outcomes data. Anchoring videos were not contained in the Test-Set, and

165 were chosen as representative videos of each skill level by adjudication by the study team. Grading 166 sessions were conducted in double-blinded fashion by the lead author (DJP) and individual experts (BS,

167 MR, GZ, DAD, referred to as S1-S4). Given high concordance, mean and mode are reported for experts 168 ('S').

170 Validation Analysis:

171 We conducted two experiments to evaluate model and expert concordance. In experiment one, two

172 videos were identified in the Test-Set which where a critical error occurred shortly after the 1-minute

173 video sample concluded (i.e., not shown to the model or surgeons). The model and all surgeons

174 predicted, incorrectly, that both videos were successes. A new, one minute clip was generated showing

175 the critical error and its aftermath. These new clips were evaluated by one of the human experts and

176 SOCALNet.

178 In a second experiment, the three best (least blood loss, successes) and worst (most blood loss, failures)

179 videos were identified from within the Test-Set. Composite 'best' and 'worst' videos were constructed

180 by combining the first 20 seconds of each of the three best and worst trials in each possible order

181 permutation (6 'best', 6 'worst' videos). The twelve composite videos were then presented to

182 SOCALNet.

184 Statistical Analysis:

185 Blood loss prediction was reported using mean error, root mean square error (RMSE), and Pearson's 186 correlation coefficients. Categorical inter-rater reliability was calculated using Cohen's Kappa and 187 Krippendorff's alpha for more than two raters. Continuous inter-rater reliability was calculated using 188 Pearson's correlation coefficient and an inter-rater correlation coefficient (ICC) ( $>2$ groups; using a 189 two-way random effects ICC model ). ${ }^{30}$ We used Fisher's exact test for categorical comparisons. We 190 performed analysis in Python with SciPy. ${ }^{31}$

\section{Results:}

194 Table 1 lists predictions and ground truth data. There were 11 successful trials and 9 failed trials in the

195 Test Set, with mean blood loss of $568 \mathrm{~mL}$ (range $20-1640 \mathrm{~mL}$, mean success $=323 \mathrm{~mL}$, mean failure $=868$ 
medRxiv preprint doi: https://doi.org/10.1101/2022.01.22.22269640; this version posted January 23, 2022. The copyright holder for this preprint (which was not certified by peer review) is the author/funder, who has granted medRxiv a license to display the preprint in It is made available under a CC-BY-NC-ND 4.0 International license .

196

197

198

199

200

201

202

203

204

205

206

207

208

209

210

211

212

213

214

215

216

217

218

219

220

221

222

223 Supplemental Table 2 reports model-validation experiments. In two trials, experts and SOCALNet 224 predicted success, but the surgeon failed due to a critical error shortly after the end of the one-minute 225 clip (therefore unseen by experts and SOCALNet). When we included the critical error, the model

$\mathrm{mL})$. Experts correctly predicted outcome in $55 / 80$ predictions $(69 \%$, Sensitivity: $79 \%$, Specificity: $56 \%$ ). Expert predictions were concordant, with one dissent in 80 ratings (Fleiss' kappa $=0.95$ ). The average root mean square error (RMSE) for blood loss prediction of surgeons was $351 \mathrm{~mL}$ (mean error $=-131 \mathrm{~mL}$, average $\mathrm{R}^{2}=.70$ ). Expert ICC was high at 0.72 .

Figure 2, and Supplemental Table 1 demonstrates the relationship between prediction confidence, surgeon skill and prediction accuracy. Experts were most accurate when maximally confident (5/5 confidence, accuracy $88 \%$ ) or viewing a surgeon they rated as having minimal (Likert scale 1, accuracy $92 \%$ ) or maximal skill (Likert scale 5, accuracy 79\%). Predictions with non-maximal confidence (levels $2-4$,) were only marginally better than chance (53\%, $\mathrm{p}=0.02$ compared to maximal confidence). Predictions of intermediate skill surgeons were also less accurate (levels $2-4,63 \%, p=0.04$ compared to composite $1 / 5$ and $5 / 5$ skill).

SOCALNet correctly predicted outcome in $17 / 20$ trials ( $85 \%$, Sensitivity: $100 \%$, Specificity: $66 \%$ ), noninferior to surgeons $(\mathrm{p}=0.12)$. The model predicted blood loss with a RMSE of $295 \mathrm{~mL}$ (mean error $=-57 \mathrm{~mL}, \mathrm{R}^{2}=.74$ ) (Figure 3). The model and experts all predicted outcome correctly in 13/20 trials. In four trials, the model was correct and all experts incorrect, in one trial the model was incorrect, and all experts correct, and two trials all were incorrect (Figure 4). Correlation $\left(\mathrm{R}^{2}\right)$ between blood loss estimates for the model, experts and ground truth are shown in Supplemental Figure 1, and range from 0.53-0.93. Correlation between the model and the average surgeon blood loss estimate was 0.73 , ranging from 0.53 to 0.74 for individual surgeons (Table 1).

We then evaluated trials above the $50^{\text {th }}$ percentile for blood loss, where blood loss exceeded $500 \mathrm{~mL}$ and transfusion might be needed. The model predicted a blood loss estimate above $500 \mathrm{~mL}$ in $80 \%(8 / 10)$ compared to experts $47.5 \%$ (19/40); this difference was not statistically significant ( $\mathrm{p}=0.09)$. accurately predicted 'failure', as did an expert. In a second experiment, SOCALNet viewed six composite 'Best' trials and uniformly predicted success with low blood loss (328-473 mL); conversely, in six composite 'Worst' videos the model uniformly predicted failure with high blood loss (792$794 \mathrm{~mL})$. 
medRxiv preprint doi: https://doi.org/10.1101/2022.01.22.22269640; this version posted January 23, 2022. The copyright holder for this preprint (which was not certified by peer review) is the author/funder, who has granted medRxiv a license to display the preprint in It is made available under a CC-BY-NC-ND 4.0 International license .

\section{Discussion:}

234 To address the need for datasets depicting surgical adverse events we created SOCAL, a public video 235 dataset of 147 attempts to control carotid injury in high-fidelity perfused cadavers. In this work we 236 compared human expert predictions of outcome using one minute of video from 20 trials in the dataset 237 to those of a DNN (SOCALNet). Compared to expert benchmarks, SOCALNet met or surpassed expert 238 prediction performance, despite its relatively primitive architecture and small training data size relative 239 to CV tasks. We synthesized counterfactual videos of excellent and poor surgeon performance to 240 challenge SOCALNet, and it correctly predicted the outcomes in these challenges. SOCALNet and 241 other CV methods can aid surgeons by quantifying and predicting outcome during surgical events, and 242 in automatic video review. The absence of video datasets containing adverse events is a critical unmet 243 need preventing the development of predictive models to improve surgical care.

245 Benchmark Performance of Human Experts:

246 Expert predictions were highly concordant, indicating that experts detected similar signals of blood loss 247 and outcome (cross-correlation: $\mathrm{R}^{2}=0.74-0.93$, Kappa for success prediction=0.95). Experts had 248 uniform definitions of success (hemostasis) and were familiar with the stepwise progression of a well249 described technique. ${ }^{18,32}$ Thus, it is reasonable to conclude that using the first minute of video of a bleeding event, human experts detect signals predictive of blood loss and task outcome.

Although experts had reasonably accurate outcome and blood loss predictions ( $69 \%$ accuracy, $\left.\mathrm{R}^{2}=0.7\right)$, experts systematically overestimate surgeon success and underestimate bleeding: 4/6 of expert errors were false 'success' predictions, experts systematically underestimated blood loss by $131 \mathrm{~mL}$ and experts failed to identify $52 \%$ of high blood loss (above $500 \mathrm{~mL}$ ) events. This post-hoc cutoff of $500 \mathrm{~mL}$ represents a potential clinical marker of need for transfusion. The tendency for human experts to underestimate blood loss is well documented, ${ }^{33-36}$ corroborated by our findings, and may result in delayed recognition of life-threatening hemorrhage.

260 To validate individual ratings, we asked experts to provide their confidence in each prediction, and 261 perceived skill rating of the participating surgeon. Maximally confident predictions were more likely to 262 be correct, as expected from prior work. ${ }^{33,34,37}$ Similarly, predictions were most accurate when evaluating highest and lowest-skilled surgeons (skill rating 1 or 5), but scarcely better than chance when evaluating intermediate surgeons. Intermediate skill surgeons comprised half of all surgeons and may benefit greatly from performance assessments.

During a real vascular injury, estimation ability of the average surgeon is likely to be inferior to our experts calmly rating a single stereotyped task after training with videos of known blood loss. Experts' systematic underestimation of blood loss and struggle to assess performance of intermediate surgeons 
medRxiv preprint doi: https://doi.org/10.1101/2022.01.22.22269640; this version posted January 23, 2022. The copyright holder for this preprint (which was not certified by peer review) is the author/funder, who has granted medRxiv a license to display the preprint in It is made available under a CC-BY-NC-ND 4.0 International license .

represents a chasm in surgeon-assessment proficiency. Surgical patients may benefit from novel methods that improve on these benchmarks.

SOCALNet Performance Compared to Experts:

We designed a primitive deep-learning architecture containing a standard CNN and a recurrent neural network, which we call SOCALNet. We provided SOCALNet with short videos from a much smaller training dataset than is customary in CV. Despite these disadvantages, SOCALNet made statistically non-inferior (and numerically superior) outcome predictions and superior blood loss predictions compared to human experts. SOCALNet's predictions of blood loss had a smaller mean underestimation and standard error. Unlike experts, SOCALNet predictions were accurate for intermediate-skill surgeons.

The advantages of SOCALNet support the development of computer vision tools for surgical video review and as potential teammates for surgeons. ${ }^{38}$ SOCALNet demonstrates that $\mathrm{CV}$ models can provide accurate, clinically meaningful analyses of surgical outcome from video. Future models could leverage the vast but largely untapped collections of surgical videos. Workflows developed in building SOCALNet can guide model deployment for other surgical adverse events. Human-AI teaming is a validated concept in other domains. ${ }^{39-41}$ A SOCALNet-and-expert combined team (with model as a tiebreaker, particularly when expert confidence was low) would have generated 18/20 correct predictions. Furthermore, the only two inaccurate predictions from this teaming occurred when a critical error was made after the video ceased, and these errors were detected by the model and experts. If utilized at scale, AI-driven video analysis may quantify comparisons of surgical technique, provide realtime feedback for trainees, or provide guidance during rare scenarios a surgeon may not have encountered (e.g. vascular injury) but the model has been trained on. ${ }^{38}$

SOCALNet has room for improvement. For adverse events, the 1) accurate estimation of high-volume blood-loss and 2) detection of task failures may be prioritized as exsanguination is life-threatening. SOCALNet blood loss predictions exhibited more robust central tendency than experts, resulting in better predictions for typical performances. However, when grading edge cases of the two worst surgeons in the Test Set, SOCALNet underestimated blood loss (absolute error of $790-800 \mathrm{~mL}$ on videos exceeding $1.5 \mathrm{~L}$ of blood loss). In predicting failure (specificity), both experts and SOCALNet showed limitations (Specificity $=0.56,0.66$ respectively); however, improving expert predictions are challenging, and most surgeons are non-experts. Accordingly, applying CV optimization techniques to AI models (e.g. cost-sensitive classification, oversampling) may be preferred. ${ }^{42,43}$

Surgical Adverse Event Video Datasets: An Unmet Need in Surgical Safety: 
medRxiv preprint doi: https://doi.org/10.1101/2022.01.22.22269640; this version posted January 23, 2022. The copyright holder for this preprint (which was not certified by peer review) is the author/funder, who has granted medRxiv a license to display the preprint in It is made available under a CC-BY-NC-ND 4.0 International license .

306 A growing body of evidence supports the quantitative analysis of surgical video. ${ }^{22,44-47}$ One fundamental

307 discovery has been the detection of signals in surgical video that predict patient outcome: surgeons have 308 heterogeneous skill resulting in heterogeneous outcomes. ${ }^{14,44,45,48}$ Although low-skill surgeons are more

309 likely to have adverse intraoperative events, video of these events has not been systematically studied.

310 Instead of studying surgical video, studies describe adverse events using textual medical records,

311 radiography, and laboratory results. Analysis of these extra-operative records and correlations with pre-

312 operative risk factors and post-operative management can be useful. ${ }^{4-53}$ However, this research omits

313 a crucial determinant of the outcome of the surgical patient: the surgical event itself. This omission

314 limits root-cause analysis to only the extra-operative universe and prevents evaluation of the technical

315 maneuvers and patient anatomic conditions that make adverse events more likely. Unlike textual

316 records, surgical video depicts all visualized surgeon movements and patient anatomy, making video

317 uniquely suited for the study of operative events. The results of the present study begin to demonstrate

318 the value of studying video of surgical adverse events.

We propose the creation of large, multi-center datasets of surgical videos that includes adverse events. ${ }^{54,55}$ Video datasets of surgical adverse events can be leveraged using predictive models (e.g., SOCALNet) which can detect intraoperative events, evaluate performance and quantify technique. This study was supported the North American Skull Base Society, whose mission is to promote scientific advancement, share outcomes data for education and to advance outcomes research. Groups such as the Michigan Bariatric Surgery Collaborative and the Michigan Urologic Surgery Improvement Consortium have conducted similar work and we hope to call their attention to adverse events in addition to routine procedures. ${ }^{56,57}$ National organizations capable of soliciting large bodies of data should prioritize collecting adverse event videos and apply technical innovations adopted by other medical fields to ensure privacy and confidentiality. ${ }^{58-60}$ National organizations can also facilitate the scaling of expert labeling. Small groups face long delays in accruing sufficient cases and labeling video. In this study, despite a long term track record of collaboration amongst our team, it required two months for our experts to review 20 minutes of aggregated video. ${ }^{61}$ Collaborative efforts may be able to require video review as a condition of membership.

Finally, high-fidelity simulation enables analysis of rare surgical events. Curating 150 videos of real carotid injuries would require tens of thousands of cases, an impossible task without streamlined datasharing mechanisms; using perfused cadavers and real instruments we collected hundreds of observations of this otherwise rare event. Videos in the simulated environment can complement surgical video datasets that otherwise depict thousands of uncomplicated cases and only a few rare events. ${ }^{14,15,17,18,62-65}$ As more surgical video datasets are developed, we can follow the 'sim-to-real' process where models are trained on virtual data and then fine-tuned and validated in the real environment. ${ }^{66-68}$ 
medRxiv preprint doi: https://doi.org/10.1101/2022.01.22.22269640; this version posted January 23, 2022. The copyright holder for this preprint (which was not certified by peer review) is the author/funder, who has granted medRxiv a license to display the preprint in It is made available under a CC-BY-NC-ND 4.0 International license .

\section{Limitations:}

345 Our study has several limitations. First, validation on clinical video is a clear next step, although 346 accruing a corpus of carotid injury video would likely require substantial national efforts. Second,

347 results from carotid injuries may not transfer to other vascular injuries, and vascular injuries differ from

348 other adverse events. Rather than diminishing our results, these complementary challenges showcase

349 the depth of unmet need within surgical-video data science. Separately from these study design

350 limitations, SOCALNet ingests ground truth tool annotations as input, which requires pre-processing

351 of data and is thus not fully automated. ${ }^{69-71}$ The lack of curated surgical video datasets remain a major

352 limitation for future work.

\section{Conclusion:}

355 Experts and a neural network can predict the outcome of surgical hemorrhage from the first minute of video of the adverse event. Neural network-based architectures can already achieve human or suprahuman performance at predicting clinically relevant outcomes from video. To improve outcomes of surgical patients, advances in quantitative and predictive methods should be applied to newly collected video datasets containing adverse events.

\section{Data Availability:}

The datasets generated during and/or analyzed during the current study are available in the figshare repository, link: https://doi.org/10.6084/m9.figshare.15132468.v1

\section{References}

1. Lee, Y. F. et al. Unplanned Robotic-Assisted Conversion-to-Open Colorectal Surgery is Associated with Adverse Outcomes. J Gastrointest Surg 22, 1059-1067 (2018).

2. England, E. C. et al. REBOA as a rescue strategy for catastrophic vascular injury during robotic surgery. J Robot Surg 14, 473-477 (2020).

3. Sandadi, S. et al. Recognition and management of major vessel injury during laparoscopy. J Minim Invasive Gynecol 17, 692-702 (2010).

4. Hemingway, J. F. et al. Intraoperative consultation of vascular surgeons is increasing at a major American trauma center. J Vasc Surg 74, 1581-1587 (2021).

5. Laws, E. R. Vascular complications of transsphenoidal surgery. Pituitary 2, 163-170 (1999).

6. Beekley, A. C. Damage control resuscitation: a sensible approach to the exsanguinating surgical patient. Crit Care Med 36, S267-274 (2008).

7. Tisherman, S. A. Management of Major Vascular Injury: Open. Otolaryngol Clin North Am 49, 809-817 (2016).

8. Melnic, C. M., Heng, M. \& Lozano-Calderon, S. A. Acute Surgical Management of Vascular Injuries in Hip and Knee Arthroplasties. J Am Acad Orthop Surg 28, 874-883 (2020). 
medRxiv preprint doi: https://doi.org/10.1101/2022.01.22.22269640; this version posted January 23, 2022. The copyright holder for this preprint (which was not certified by peer review) is the author/funder, who has granted medRxiv a license to display the preprint in It is made available under a CC-BY-NC-ND 4.0 International license .

9. Quasarano, R. T., Kashef, M., Sherman, S. J. \& Hagglund, K. H. Complications of gynecologic laparoscopy. J Am Assoc Gynecol Laparosc 6, 317-321 (1999).

10. Asfour, V., Smythe, E. \& Attia, R. Vascular injury at laparoscopy: a guide to management. J Obstet Gynaecol 38, 598-606 (2018).

11. Filis, K. et al. Iatrogenic Vascular Injuries of the Abdomen and Pelvis: The Experience at a Hellenic University Hospital. Vasc Endovascular Surg 53, 541-546 (2019).

12. Arora, S. et al. Stress impairs psychomotor performance in novice laparoscopic surgeons. Surg Endosc 24, 2588-2593 (2010).

13. Jukes, A. K. et al. Stress response and communication in surgeons undergoing training in endoscopic management of major vessel hemorrhage: a mixed methods study. Int Forum Allergy Rhinol 7, 576-583 (2017).

14. Donoho, D. A. et al. Improved surgeon performance following cadaveric simulation of internal carotid artery injury during endoscopic endonasal surgery: training outcomes of a nationwide prospective educational intervention. Journal of Neurosurgery 1, 1-9 (2021).

15. Shen, J. et al. Objective Validation of Perfusion-Based Human Cadaveric Simulation Training Model for Management of Internal Carotid Artery Injury in Endoscopic Endonasal Sinus and Skull Base Surgery. Oper Neurosurg (Hagerstown) 15, 231-238 (2018).

16. Zada, G. et al. Development of a Perfusion-Based Cadaveric Simulation Model Integrated into Neurosurgical Training: Feasibility Based On Reconstitution of Vascular and Cerebrospinal Fluid Systems. Oper Neurosurg (Hagerstown) 14, 72-80 (2018).

17. Donoho, D. A. et al. Costs and training results of an objectively validated cadaveric perfusion-based internal carotid artery injury simulation during endoscopic skull base surgery. Int Forum Allergy Rhinol 9, 787-794 (2019).

18. Pham, M. et al. A Perfusion-based Human Cadaveric Model for Management of Carotid Artery Injury during Endoscopic Endonasal Skull Base Surgery. J Neurol Surg B 75, 309-313 (2014).

19. Ciric, I., Ragin, A., Baumgartner, C. \& Pierce, D. Complications of transsphenoidal surgery: results of a national survey, review of the literature, and personal experience. Neurosurgery 40, 225-236; discussion 236-237 (1997).

20. AlQahtani, A. et al. Assessment of Factors Associated With Internal Carotid Injury in Expanded Endoscopic Endonasal Skull Base Surgery. JAMA Otolaryngol Head Neck Surg (2020) doi:10.1001/jamaoto.2019.4864.

21. Kugener, G. et al. Deep Neural Networks Can Accurately Detect Blood Loss and Hemorrhage Control Task Success from Intraoperative Video. Neurosurgery (Accepted).

22. Pangal, D. J. et al. Surgical Video-Based Automated Performance Metrics Predict Blood Loss and Success of Simulated Vascular Injury Control in Neurosurgery: A Pilot Study. Journal of Neurosurgery (Accepted).

23. Pangal, D. J. et al. Technical Note: A Guide to Annotation of Neurosurgical Intraoperative Video for Machine Learning Analysis and Computer Vision. World Neurosurg (2021) doi:10.1016/j.wneu.2021.03.022.

24. Kugener, G., Pangal, D. J. \& Zada, G. Simulated Outcomes following Carotid Artery Laceration. (2021) doi:10.6084/m9.figshare.15132468.v1.

25. Paper Information / Code Submission Policy. https://nips.cc/Conferences/2021/PaperInformation/CodeSubmissionPolicy.

26. Squire 2.0 (Standards for Quality Improvement Reporting Excellence): Revised Publication Guidelines From a Detailed Consensus Process | American Journal of Critical Care $\mid$ American Association of Critical-Care Nurses. https://aacnjournals.org/ajcconline/article-abstract/24/6/466/4045/Squire-2-0-Standardsfor-Quality-Improvement. 
medRxiv preprint doi: https://doi.org/10.1101/2022.01.22.22269640; this version posted January 23, 2022. The copyright holder for this preprint (which was not certified by peer review) is the author/funder, who has granted medRxiv a license to display the preprint in perpetuity.

perpetuity.

435

436

437

438

439

440

441

442

443

444

445

446

447

448

449

450

451

452

453

454

455

456

457

458

459

460

461

462

463

464

465

466

467

468

469

470

471

472

473

474

475

476

477

478

479

480

481

482

483

484

27. He, K., Zhang, X., Ren, S. \& Sun, J. Deep Residual Learning for Image Recognition. arXiv:1512.03385 [cs] (2015).

28. Deng, J. et al. ImageNet: A large-scale hierarchical image database. in 2009 IEEE Conference on Computer Vision and Pattern Recognition 248-255 (2009). doi:10.1109/CVPR.2009.5206848.

29. Yengera, G., Mutter, D., Marescaux, J. \& Padoy, N. Less is More: Surgical Phase Recognition with Less Annotations through Self-Supervised Pre-training of CNN-LSTM Networks. arXiv:1805.08569 [cs] (2018).

30. Koo, T. K. \& Li, M. Y. A Guideline of Selecting and Reporting Intraclass Correlation Coefficients for Reliability Research. J Chiropr Med 15, 155-163 (2016).

31. Virtanen, P. et al. SciPy 1.0: fundamental algorithms for scientific computing in Python. Nat Methods 17, 261-272 (2020).

32. Kassir, Z. M., Gardner, P. A., Wang, E. W., Zenonos, G. A. \& Snyderman, C. H. Identifying Best Practices for Managing Internal Carotid Artery Injury During Endoscopic Endonasal Surgery by Consensus of Expert Opinion. Am J Rhinol Allergy 19458924211024864 (2021) doi:10.1177/19458924211024864.

33. Thomas, S. et al. Measured versus Estimated Blood Loss: Interim Analysis of a Prospective Quality Improvement Study. Am Surg 86, 228-231 (2020).

34. Lopez-Picado, A., Albinarrate, A. \& Barrachina, B. Determination of Perioperative Blood Loss: Accuracy or Approximation? Anesth Analg 125, 280-286 (2017).

35. Saoud, F. et al. Validation of a new method to assess estimated blood loss in the obstetric population undergoing cesarean delivery. Am J Obstet Gynecol 221, 267.e1-267.e6 (2019).

36. Rubenstein, A. F., Zamudio, S., Douglas, C., Sledge, S. \& Thurer, R. L. Automated Quantification of Blood Loss versus Visual Estimation in 274 Vaginal Deliveries. Am J Perinatol (2020) doi:10.1055/s-0040-1701507.

37. Serapio, E. T., Pearlson, G. A., Drey, E. A. \& Kerns, J. L. Estimated versus measured blood loss during dilation and evacuation: an observational study. Contraception 97, 451-455 (2018).

38. Ward, T. M. et al. Computer vision in surgery. Surgery 169, 1253-1256 (2021).

39. Maia Chess. https://maiachess.com.

40. Zhang, R., McNeese, N. J., Freeman, G. \& Musick, G. 'An Ideal Human': Expectations of AI Teammates in Human-AI Teaming. Proc. ACM Hum.-Comput. Interact. 4, 246:1246:25 (2021).

41. Human-AI collaboration inspires tyre innovation.

42. Elkan, C. The foundations of cost-sensitive learning. in Proceedings of the 17th international joint conference on Artificial intelligence - Volume 2 973-978 (Morgan Kaufmann Publishers Inc., 2001).

43. Teh, K., Armitage, P., Tesfaye, S., Selvarajah, D. \& Wilkinson, I. D. Imbalanced learning: Improving classification of diabetic neuropathy from magnetic resonance imaging. PLOS ONE 15, e0243907 (2020).

44. Birkmeyer, J. D. et al. Surgical Skill and Complication Rates after Bariatric Surgery. New England Journal of Medicine 369, 1434-1442 (2013).

45. Brajcich, B. C. et al. Association Between Surgical Technical Skill and Long-term Survival for Colon Cancer. JAMA Oncol (2020) doi:10.1001/jamaoncol.2020.5462.

46. Chhabra, K. R., Thumma, J. R., Varban, O. A. \& Dimick, J. B. Associations Between Video Evaluations of Surgical Technique and Outcomes of Laparoscopic Sleeve Gastrectomy. JAMA Surg 156, e205532 (2021).

47. Greenberg, C. C., Dombrowski, J. \& Dimick, J. B. Video-Based Surgical Coaching: An Emerging Approach to Performance Improvement. JAMA Surg 151, 282-283 (2016). 
medRxiv preprint doi: https://doi.org/10.1101/2022.01.22.22269640; this version posted January 23, 2022. The copyright holder for this preprint (which was not certified by peer review) is the author/funder, who has granted medRxiv a license to display the preprint in It is made available under a CC-BY-NC-ND 4.0 International license .

48. Stulberg, J. J. et al. Association Between Surgeon Technical Skills and Patient Outcomes. JAMA Surg (2020) doi:10.1001/jamasurg.2020.3007.

49. Elsamadicy, A. A. et al. Reduced Impact of Obesity on Short-Term Surgical Outcomes, Patient-Reported Pain Scores, and 30-Day Readmission Rates After Complex Spinal Fusion ( $>/=7$ Levels) for Adult Deformity Correction. World neurosurgery 127, e108e113 (2019).

50. Jones, D. et al. Multicentre, prospective observational study of the correlation between the Glasgow Admission Prediction Score and adverse outcomes. BMJ Open 9, e026599 (2019).

51. Arango-Lasprilla, J. C. et al. Predictors of Extended Rehabilitation Length of Stay After Traumatic Brain Injury. Archives of Physical Medicine and Rehabilitation 91, 1495-1504 (2010).

52. Giannini, A. et al. Predictors of postoperative overall and severe complications after surgical treatment for endometrial cancer: The role of the fragility index. Int J Gynaecol Obstet 148, 174-180 (2020).

53. Simpson, A. M., Donato, D. P., Kwok, A. C. \& Agarwal, J. P. Predictors of complications following breast reduction surgery: A National Surgical Quality Improvement Program study of 16,812 cases. J Plast Reconstr Aesthet Surg 72, 43-51 (2019).

54. NEUROSURGERY Journal. Carotid Injury in Endonasal Surgery. (2013).

55. NEUROSURGERY Journal. Managing Arterial Injury in Endoscopic Skull Base Surgery. (2015).

56. Home | MBSC Coordinating Center. Michigan Bariatric $S$ https://www.mbscsurgery.org.

57. Michigan Urological Surgery Improvement Collaborative (MUSIC). https://musicurology.com/.

58. Rieke, N. et al. The future of digital health with federated learning. npj Digit. Med. 3, 1-7 (2020).

59. Dou, Q. et al. Federated deep learning for detecting COVID-19 lung abnormalities in CT: a privacy-preserving multinational validation study. NPJ Digit Med 4, 60 (2021).

60. Willemink, M. J. et al. Preparing Medical Imaging Data for Machine Learning. Radiology 295, 4-15 (2020).

61. Lendvay, T. S., White, L. \& Kowalewski, T. Crowdsourcing to Assess Surgical Skill. JAMA Surg 150, 1086-1087 (2015).

62. Winer, J. L. et al. Cerebrospinal fluid reconstitution via a perfusion-based cadaveric model: feasibility study demonstrating surgical simulation of neuroendoscopic procedures. J Neurosurg 123, 1316-1321 (2015).

63. Christian, E. A. et al. Perfusion-based human cadaveric specimen as a simulation training model in repairing cerebrospinal fluid leaks during endoscopic endonasal skull base surgery. J Neurosurg 129, 792-796 (2018).

64. Strickland, B. A. et al. The Use of a Novel Perfusion-Based Human Cadaveric Model for Simulation of Dural Venous Sinus Injury and Repair. Oper Neurosurg (Hagerstown) 19, E269-E274 (2020).

65. Bakhsheshian, J. et al. The use of a novel perfusion-based cadaveric simulation model with cerebrospinal fluid reconstitution comparing dural repair techniques: a pilot study. The Spine Journal 17, 1335-1341 (2017).

66. Closing the Simulation-to-Reality Gap for Deep Robotic Learning. Google AI Blog http://ai.googleblog.com/2017/10/closing-simulation-to-reality-gap-for.html.

67. Christiano, P. et al. Transfer from Simulation to Real World through Learning Deep Inverse Dynamics Model. (2016). 
medRxiv preprint doi: https://doi.org/10.1101/2022.01.22.22269640; this version posted January $23,2022$. The copyright holder for this preprint (which was not certified by peer review) is the author/funder, who has granted medRxiv a license to display the preprint in It is made available under a CC-BY-NC-ND 4.0 International license

534

535

536

537

538

539

540

541

542

543

544

545

546

547

548

549

550

551

552

553

554

555
68. Bissonnette, V. et al. Artificial Intelligence Distinguishes Surgical Training Levels in a Virtual Reality Spinal Task. The Journal of Bone and Joint Surgery 101, (2019).

69. Kranzfelder, M. et al. Real-time instrument detection in minimally invasive surgery using radiofrequency identification technology. Journal of Surgical Research 185, 704-710 (2013).

70. Du, X. et al. Articulated Multi-Instrument 2-D Pose Estimation Using Fully Convolutional Networks. IEEE Transactions on Medical Imaging 37, 1276-1287 (2018).

71. Staartjes, V. E., Volokitin, A., Regli, L., Konukoglu, E. \& Serra, C. Machine Vision for Real-Time Intraoperative Anatomic Guidance: A Proof-of-Concept Study in Endoscopic Pituitary Surgery. Oper Neurosurg (Hagerstown) opab187 (2021) doi:10.1093/ons/opab187. 
medRxiv preprint doi: https://doi.org/10.1101/2022.01.22.22269640; this version posted January 23, 2022. The copyright holder for this preprint (which was not certified by peer review) is the author/funder, who has granted medRxiv a license to display the preprint in perpetuity.

It is made available under a CC-BY-NC-ND 4.0 International license

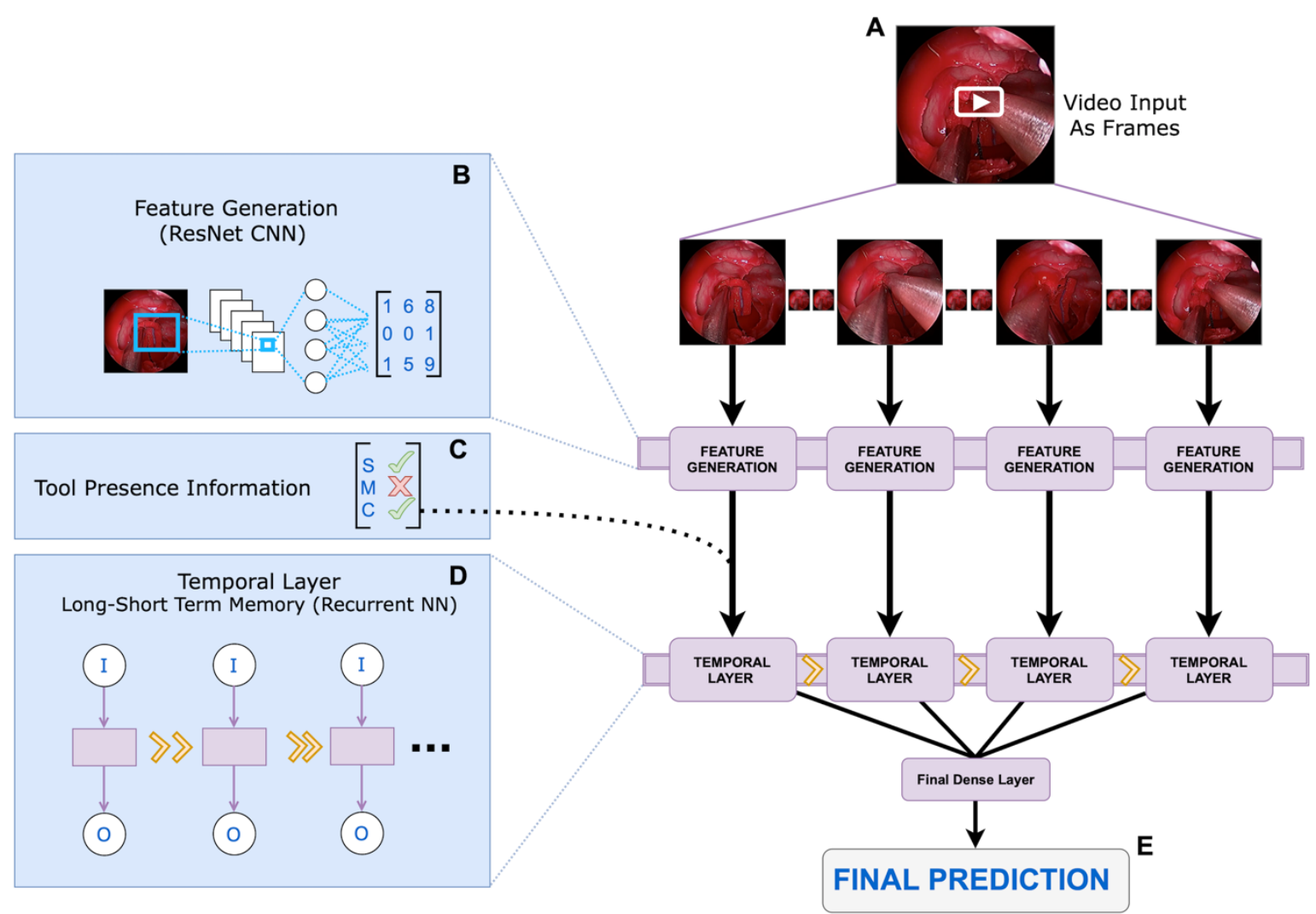

Figure 1. SOCALNet Architecture. Deep learning model used to predict blood loss and task success in critical hemorrhage control task. A) Video is snapshotted into individual frames. B) A pretrained ResNet convolutional neural network (CNN) is fine-tuned on SOCAL images from (A), to find features predictive of blood loss and task success in each individual frame. Output matrix from (B) and tool presence information (C) [e.g. Is suction (S) present? Yes (check); is Muscle (M) present? No $(\mathrm{X})$, etc] is input into a temporal layer. D) Temporal layer: Long-short-term memory (LSTM) modified recurrent neural network allowing for temporal analysis across all frames. All LSTM predictions are consolidated in one dense layer and E) a final prediction of success/failure, and blood loss (in $\mathrm{mL}$ ) is output 
medRxiv preprint doi: https://doi.org/10.1101/2022.01.22.22269640; this version posted January 23, 2022. The copyright holder for this preprint (which was not certified by peer review) is the author/funder, who has granted medRxiv a license to display the preprint in perpetuity.

It is made available under a CC-BY-NC-ND 4.0 International license .

567

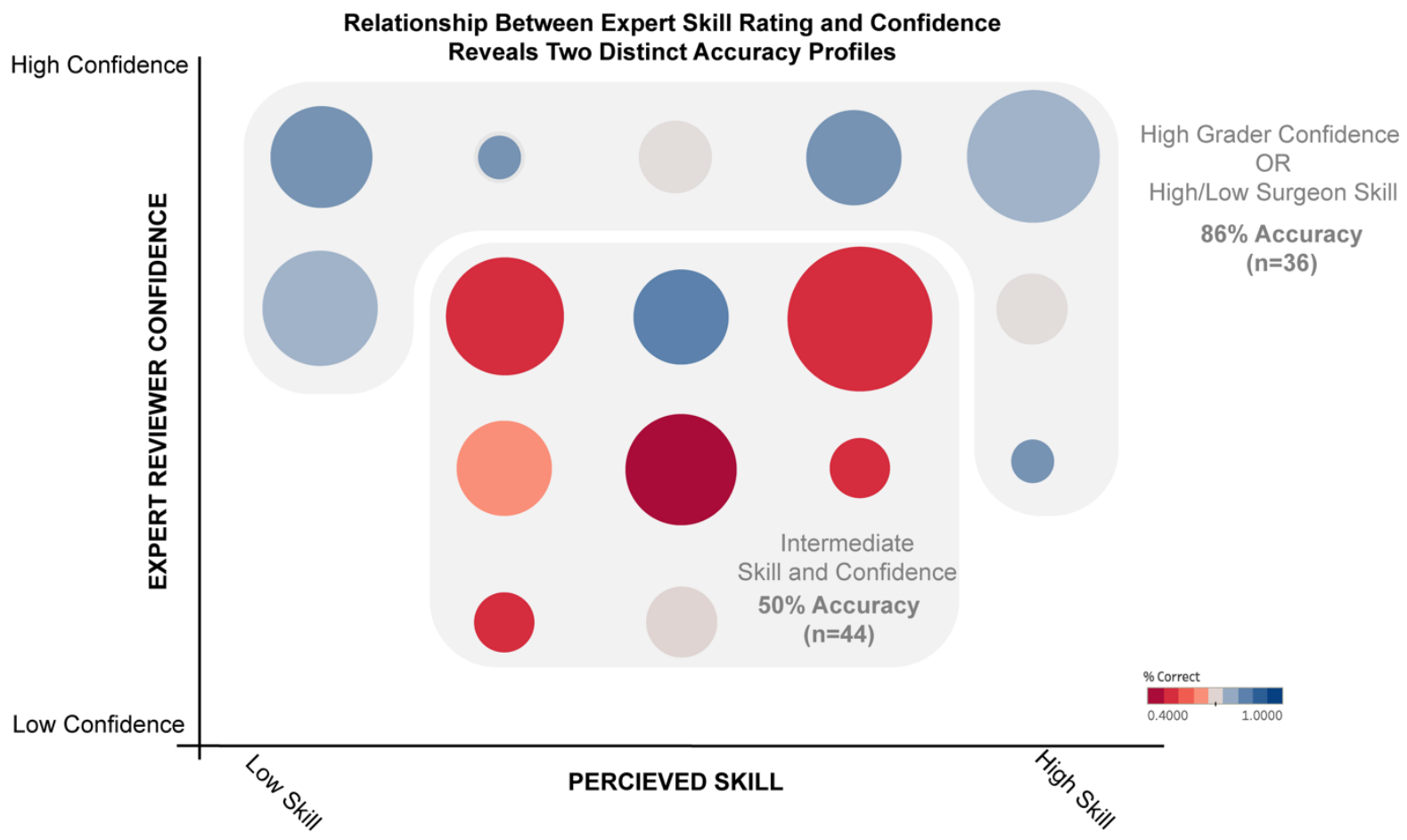

Figure 2. Association between expert confidence, surgeon skill level and accuracy of prediction. (experts) are maximally confident. For those with moderate skill or when experts have moderate confidence, prediction accuracy is lower. Size of circle denotes number of trials. Color denotes 
medRxiv preprint doi: https://doi.org/10.1101/2022.01.22.22269640; this version posted January 23, 2022. The copyright holder for this preprint (which was not certified by peer review) is the author/funder, who has granted medRxiv a license to display the preprint in perpetuity.

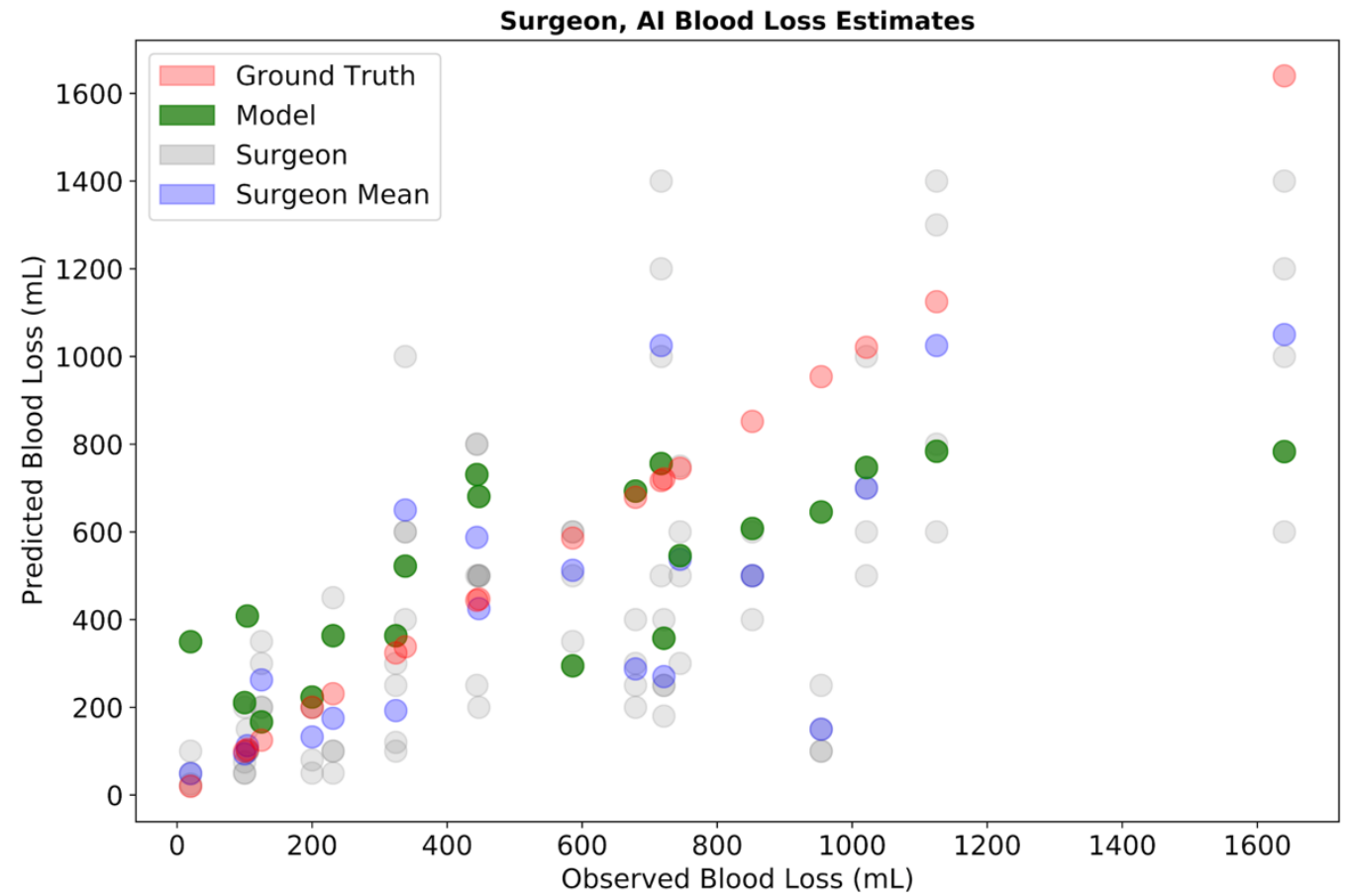

Figure 3. Expert and SOCALNet Blood Loss Quantification. Predicted versus observed blood loss estimations by individual surgeons (grey), surgeon mean (blue), and model (green). Red points represent measured blood loss (ground truth). 
medRxiv preprint doi: https://doi.org/10.1101/2022.01.22.22269640; this version posted January 23, 2022. The copyright holder for this preprint (which was not certified by peer review) is the author/funder, who has granted medRxiv a license to display the preprint in perpetuity.

586

It is made available under a CC-BY-NC-ND 4.0 International license

\section{Comparison of Model and Expert Prediction Accuracy}

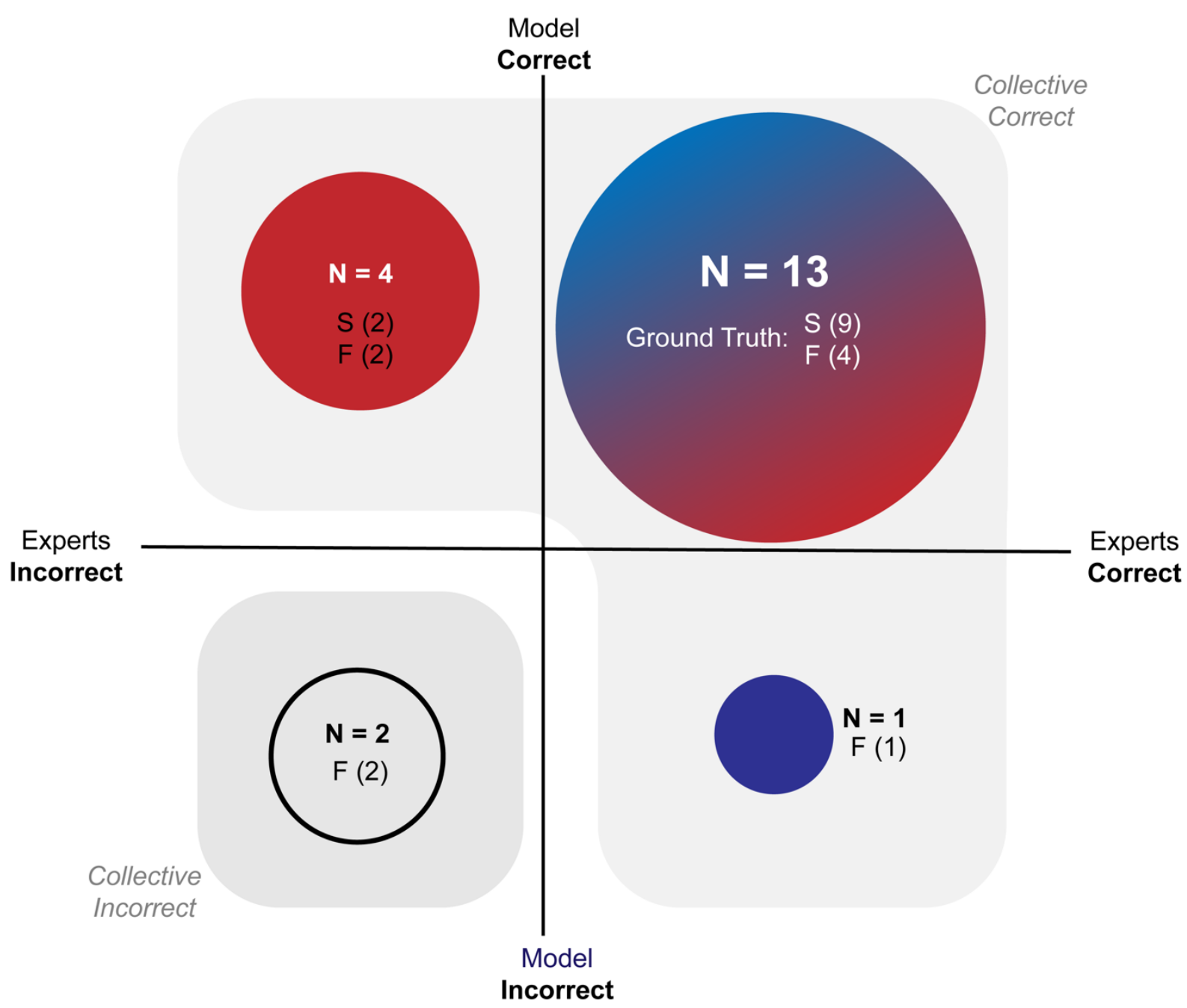

Figure 4. Outcome Predictions of Experts and SOCALNet. Outcomes of experts (Blue) and model (Red) in predicting task success using one minute of video. Circle size denotes number of trials $(\mathrm{N})$. Success (S) and failure (F) denoted underneath each N. When the union of successful predictions is taken, the model+expert grouping would successfully predict outcome in 18/20 cases. In the 2 remaining cases (bottom left quadrant), a critical error took place following the cessation of the video and was evaluated in subsequent counterfactual experiments. 
medRxiv preprint doi: https://doi.org/10.1101/2022.01.22.22269640; this version posted January 23, 2022. The copyright holder for this preprint (which was not certified by peer review) is the author/funder, who has granted medRxiv a license to display the preprint in perpetuity.

It is made available under a CC-BY-NC-ND 4.0 International license

596

597

\begin{tabular}{|c|c|c|c|c|}
\hline & $\begin{array}{l}\text { Accuracy } \\
\text { (SN \%, SP \%) }\end{array}$ & $\begin{array}{l}\text { RMSE } \\
\left(\mathbf{R}^{2}\right)\end{array}$ & $\begin{array}{l}\text { M-S Agreement: } \\
\text { Success/Failure }\end{array}$ & $\begin{array}{l}\text { M-S Agreement: }{ }^{\dagger} \\
\text { Blood Loss }\end{array}$ \\
\hline Ground Truth & $\begin{array}{l}11 \text { Success } \\
9 \text { Failures }\end{array}$ & - & - & $\begin{array}{l}\text { Avg Blood Loss: } 568 \\
\text { (Range:20-1640) }\end{array}$ \\
\hline Model & $\begin{array}{l}17 / 20(85 \%) \\
(100,66)\end{array}$ & $\begin{array}{l}295 \\
(.74)\end{array}$ & - & - \\
\hline Expert Cohort & $\begin{array}{l}55 / 80(68.75) \\
(79,56)\end{array}$ & $\begin{array}{l}351 \\
(.70)\end{array}$ & $.43^{\ddagger}$ & $0.73^{\ddagger}$ \\
\hline Surgeon 1 & $\begin{array}{l}13 / 20(65 \%) \\
(73,55)\end{array}$ & $\begin{array}{l}306 \\
(.73)\end{array}$ & .34 & .74 \\
\hline Surgeon 2 & $\begin{array}{l}14 / 20(65 \%) \\
(81,55)\end{array}$ & $\begin{array}{l}335 \\
(.66)\end{array}$ & .43 & .66 \\
\hline Surgeon 3 & $\begin{array}{l}14 / 20(65 \%) \\
(81,55)\end{array}$ & $\begin{array}{l}423 \\
(.65)\end{array}$ & .43 & .65 \\
\hline Surgeon 4 & $\begin{array}{l}14 / 20(65 \%) \\
(81,55)\end{array}$ & $\begin{array}{l}329 \\
(.74)\end{array}$ & .43 & .72 \\
\hline
\end{tabular}

598

599

600

601

602

603

604

605
Table 1. Results comparing Deep Learning Model with Expert Surgeons. SN: Sensitivity, SP:

Specificity, M-S: Model-Surgeon. *: Kappa coefficient; $\uparrow$ :inter-class coefficient; $\$$ : Inter-Surgeon Agreement: Success/Failure $=0.95$, Blood-Loss: 0.72 
medRxiv preprint doi: https://doi.org/10.1101/2022.01.22.22269640; this version posted January 23, 2022. The copyright holder for this preprint (which was not certified by peer review) is the author/funder, who has granted medRxiv a license to display the preprint in It is made available under a CC-BY-NC-ND 4.0 International license.

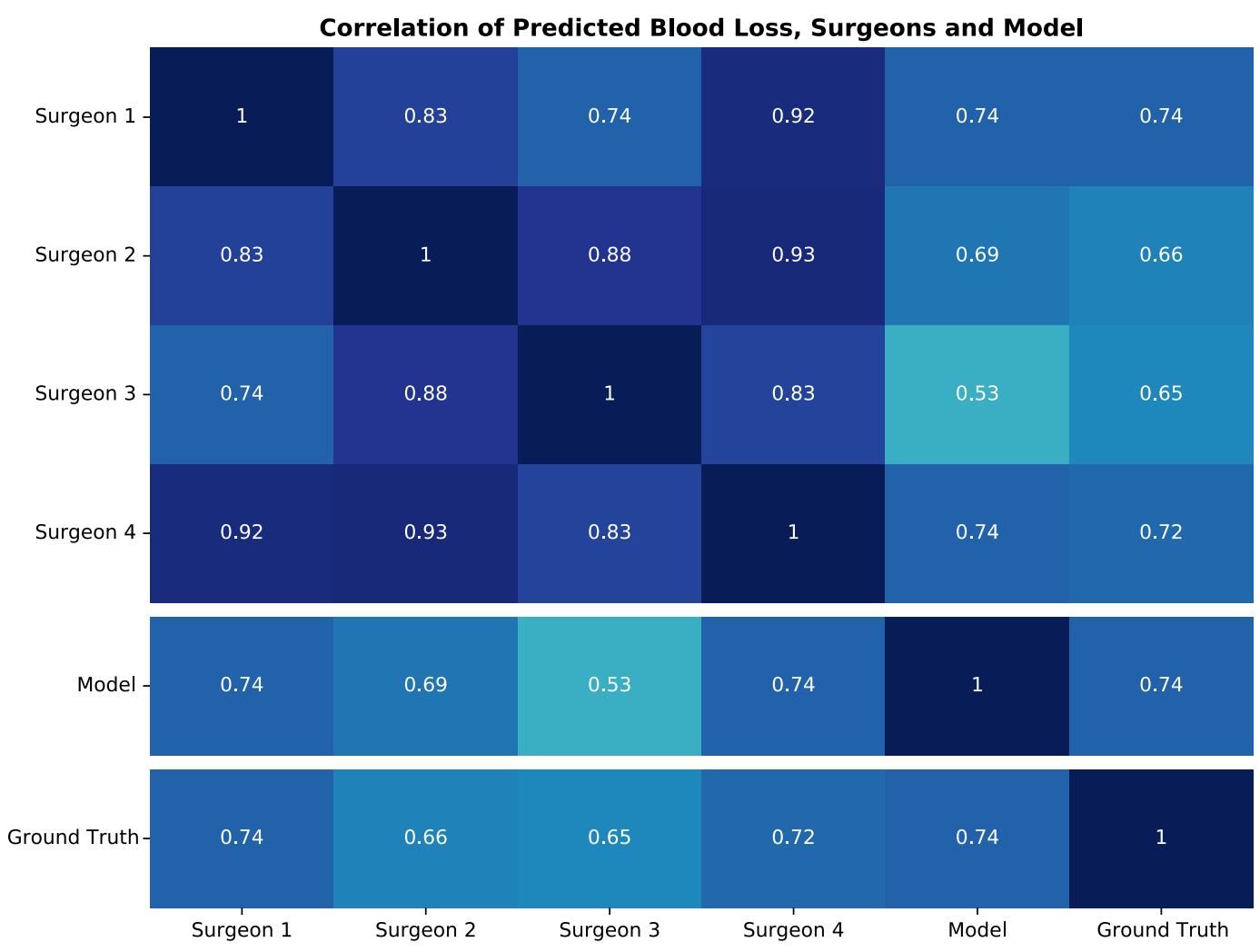

Supplemental Figure 1. Correlation $\left(\mathrm{R}^{2}\right)$ between blood loss prediction from all 4 expert surgeon graders, model, and ground truth data. 
medRxiv preprint doi: https://doi.org/10.1101/2022.01.22.22269640; this version posted January 23, 2022. The copyright holder for this preprint (which was not certified by peer review) is the author/funder, who has granted medRxiv a license to display the preprint in It is made available under a CC-BY-NC-ND 4.0 International license .

633

634

635

636

637 